\title{
RESULTS OF MEASUREMENTS AT A LABORATORY CONDENSATION HEAT EXCHANGER WITH A CORRUGATED MINICHANEL TUBE
}

\author{
PEUKERT Pavel, HRUBÝ Jan` \\ Abstract: This article present a short selection of results obtained from \\ measurements done at a laboratory condensation heat-exchanger with a \\ corrugated mini-channel tube. It also touches a little the metering method and \\ design of the heat-exchanger.
}

\section{INTRODUCTION}

Future condensation heat exchangers are required to achieve higher heat transfer rates at smaller dimensions of the exchangers, lower material costs, and lower energy loses.

An important direction in this area today is the usage of mini and micro-channels. Heat exchangers in a car air-condition system, heat-pipes in computer cooling systems, etc., represent typical applications. Although some applications appeared already a few decades ago, literature dealing with the condensation process inside mini and microchannels is not older than ten years. So far many questions in this field remain unanswered, leaving an immense potential for future development in many industrial areas.

The micro-channel effects can be observed at scales from diameters from few $\mathrm{mm}$ to tens of $\mu \mathrm{m}$ for water-vapor or water-air applications. At larger scales, the classical phase change and heat transfer models apply. At smaller scales, the continuum assumptions do not apply. The limits of these scale factors are not quite clear because a many fluid properties influence them. To illustrate the difference between the macro scale and micro scale cases, let us consider boiling in channels. In a macrochannel, bubbles occur at the overheated surface. They grow up to a so called departure size and rip off. Consequently the bubble is taken away by the bulk liquid flow. In a minichannel the bubble occupies the whole channel cross-section as it rips off. Evidently, in microchannels the influence of gravity forces are less prominent; the shear and surface tension forces play dominant roles as the scale shrinks.

As a reasonable measure for the upper scale border for microchannels, Garimella [1] suggests the Confinement number (introduced by Key and Cornwell 1997). For a microchannel, Co>0.5.

\footnotetext{
- $\quad$ Pavel PEUKERT, Technical University of Liberec, Studentská 2,461 17 Liberec 1, Czech republic; Institute of Thermomechanics AS CR, v.v.i. Dolejškova 5, CZ-182 00 Praha 8, Czech Republic,pavel.peukert@it.cas.cz;

Jan HRUBÝ Institute of Thermomechanics AS CR, v.v.i., Dolejškova 5, CZ-182 00 Praha 8, Czech Rep. hruby@it.cas.cz
}

This is an Open Access article distributed under the terms of the Creative Commons Attribution License 2.0, which permits unrestricted use, distribution, and reproduction in any medium, provided the original work is properly cited. 


$$
C o=\frac{\sqrt{\frac{\sigma}{g\left(\rho_{l}-\rho_{v}\right)}}}{D_{h}}=\frac{L}{D_{h}}
$$

Equation (1) represents a ratio of surface tension $\sigma$ and gravity forces ( $g$ - acceleration due gravity, $\rho_{l}$ - density of the liquid phase, $\rho_{V}$ - density of the vapour phase, $D_{h}-$ hydraulic diameter). This criterion should tell us when it is necessary to assume confined single elongated bubbles occupying most of a cross-section.

With this fundamental knowledge we can proceed to heat exchangers for practical applications. The basis of the studied concept of heat exchanger is a corrugated minichanel tube. It made of a copper alloy and it is divided in two parts: at the inlet the tube has a bigger diameter which shrinks at a specific length to less than a half. In Figure 1 a part of such tube is depicted. The confinement number Co, tells that microchannel effect should take apart in this channel, supposedly. Because the $C o=0,5$ limit gives for our case the boarder diameter of $5,2 \mathrm{~mm}$.

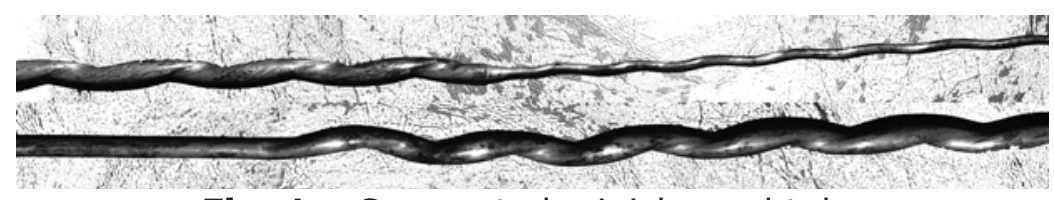

Fig. 1 - Corrugated minichannel tube

\section{SYSTEM DESIGN}

A laboratory heat-exchanger was designed with the goal to better understand the condensation process and heat transfer at specific scales and geometry. After some forethoughts, a concept was chosen allowing indirect heat transfer measurements via thermocouples and flow meters. The heat exchanger is divided in to five sections to enable, to determine the progress of the condensation process along the tube length.

The heat-exchanger is of the counter-flow type. Steam flows through the corrugated minichannel tube from the top and it condenses inside the tube. This mini-channel tube is inserted in a second tube with a selectable diameter. In the outer annular channel, the cooling water flows in the upward direction. The outer annular chanel was divided uniformly in five parts - the metering sections. "Bulk temperatures" of the cooling water are measured at the inlet and outlet of every section with thermocouples. The flow rate of cooling water is determined with a rotameter.

To verify the measurements at the cooling water side, also thermocouples are inserted at the steam entry and condensate outflow. A pressure sensor is attached ahead of the steam entry. The flow rate of the condensate is measured with a low-range rotameter. The thermocouples and the pressure sensor were connected to the HP 34970A Data Acquisition Switch Unit (today Agilent). The measurements were on-line transferred to a computer. The whole experimental layout is shown in Figure 2. 


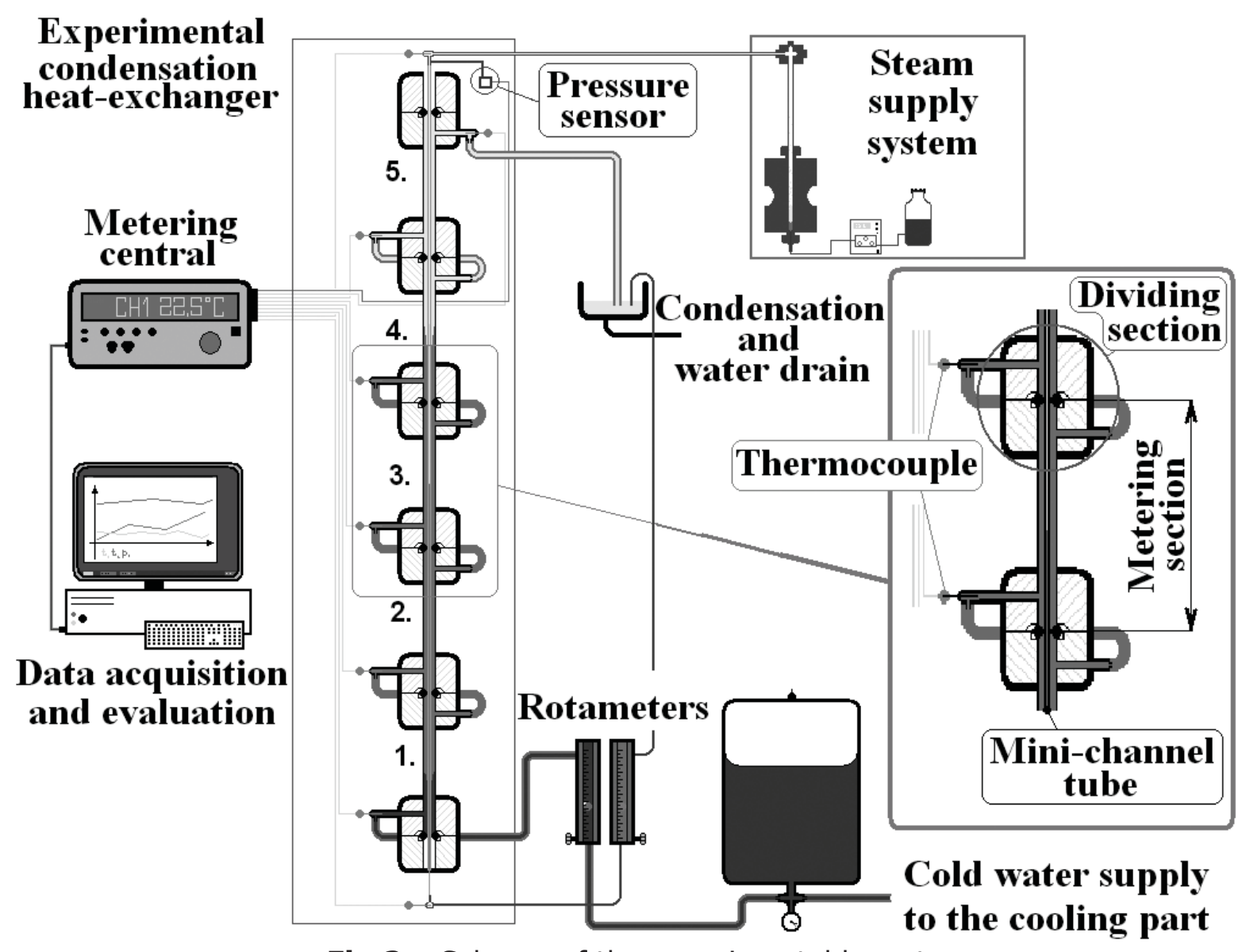

Fig. 2 - Scheme of the experimental layout

\section{Measuring procedures}

The measurements were done such that it was possible to obtain results at different steam pressure, temperature, flow rate and cooling water mass flow rate. The present first collection of results was acquired for a specified diameter of the outer tube in which the corrugated minichannel tube was inserted. In future, the influence of different outer tube diameters will be tested.

We chose the following measuring sequence. At first a series of pressures was chosen. At each pressure level, a matrix of measurements was acquired for various condensate flow rates and cooling water flow rates. The inlet steam temperature was kept approximately 10 degrees above the saturation temperature corresponding to the measured pressure in order to avoid moist steam condition at the inlet. After setting the steam pressure and temperature which determined essentially the condensate flow rate, the cooling water flow rate was varied. For each setting, readings were recorded for the thermocouples, pressure transducer, and the condensate and cooling water flow rates. The measurements were recorded after proper stabilization of the measured parameters. Dependently on the cooling water flow rate, the stabilization required 2 to 10 minutes, mainly due to the heat capacity of metallic parts of the heat exchanger. Cooling water temperature drift during the measurements was smaller than $0.5^{\circ} \mathrm{C}$ per minute. Readings of all thermocouples and pressure transducer were recorded every second for three 
minutes. Within this period, the flow rates of condensate and cooling water were checked continuously to ensure reliable data. Certain fluctuation of the flow rates could not be entirely avoided. For high flow rates, the fluctuations were typically within $1 \%$ of the reading, at maximum $2 \%$. At smallest measured flow rates, the fluctuations were within $10 \%$ of the reading.

After accomplishing the measurements thermodynamic parameters were evaluated using the IAPWS-IF97 formulation of thermodynamic properties of water and steam $[3,4]$. Specific enthalpies $h_{L, i}$ were determined for the cooling water corresponding to the inlet temperature $T_{i}$ of section number $i$, being equal to the outlet temperature of section $i-1$ for $i>=1$. The liquid pressure was taken as $0.1 \mathrm{MPa}$. Small variation of pressure, due to hydrodynamic resistances, have negligible effect on evaluated enthalpies. The heat transfer rate in section $i$ was then determined as

$i=1, \ldots, 5$

$$
\dot{Q}=\dot{m}_{L}\left(h_{L, i+1}-h_{L, i}\right) \text {, }
$$

where $\dot{m}_{L}$ is the cooling water mass flow rate. The total heat transfer was determined for the cooling water side as

and for the steam side as

$$
\dot{Q}=\dot{m}\left(h_{L, 6}-h_{L, 1}\right) \text {, }
$$

$$
\dot{Q}=\dot{m}_{V}\left(h_{V i n}-h_{\text {Cout }}\right) \text {, }
$$

where $\dot{m}_{V}$ is steam mass flow rate, $h_{V i n}$ is enthalpy of the incoming dry steam, and $h_{\text {Cout }}$ is enthalpy of the condensate at the outlet of the corrugated tube. The agreement of the total heat transfer determined in both ways was within $6 \%$. The main reason of the discrepancies is the uncertainty in mass flow measurement.

\section{RESULtS}

A large body of data was obtained from over 300 relevant measurements within approximately 55 hours of measurement time. A few of them will be discussed here.

We start with measurements at inlet steam pressure of 4.4 bar.

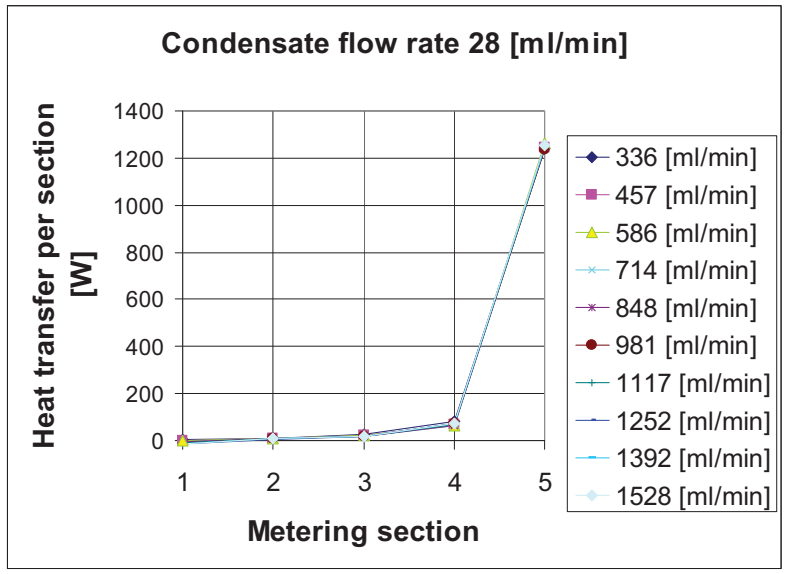

\section{Condensate flow rate $88.5[\mathrm{ml} / \mathrm{min}]$}

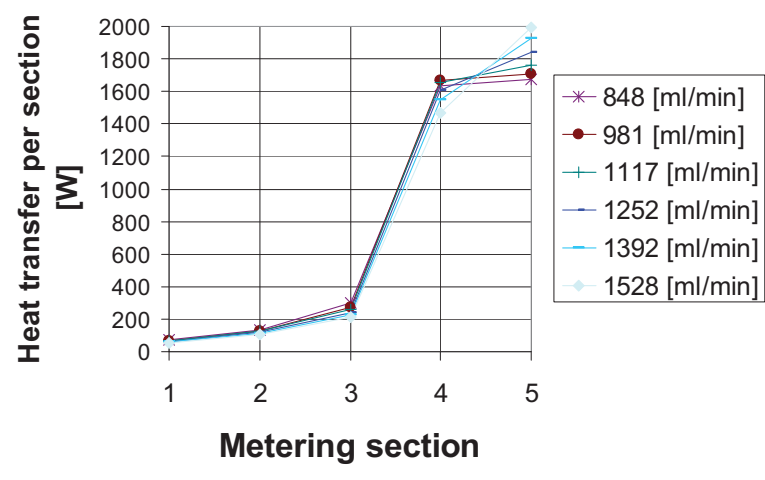

Fig.3 - Heat transfer rates per section at 4.4 bar at different cooling water flow rates with condensate flow rates of $28 \mathrm{ml} / \mathrm{min}$ and 88.5

At very low steam mass flow rates shown in Figure 3, left chart, the different cooling water flow rates make no difference in the distribution of the heat transfer. Practically all steam condenses in the first section. Only the cooling water outlet temperature changes. 
More interesting is the right-located chart in Figure 3 with a condensate flow of $88.5 \mathrm{ml} / \mathrm{min}$. Here it is apparent how the heat transfer occurs also in the $4^{\text {th }}$ section, but still its major part remains in the $5^{\text {th }}$ section. Another change could be observed in Figure 4. At relative high steam flow rates, the main part of the condensation process shifts to the middle section. Interestingly, the heat transfer rate in the $5^{\text {th }}$ section drops even below the heat transfer rate shown the left chart in Figure 3 for very low steam mass flow rate. The heat mass flow rate in the last section is thus an non-monotonous function of the steam flow rate showing a maximum. A possible interpretation is that steam bubbles occupying the whole cross section of the minichannel travel along the section, leading to an effective decrease of the heat transfer rate.

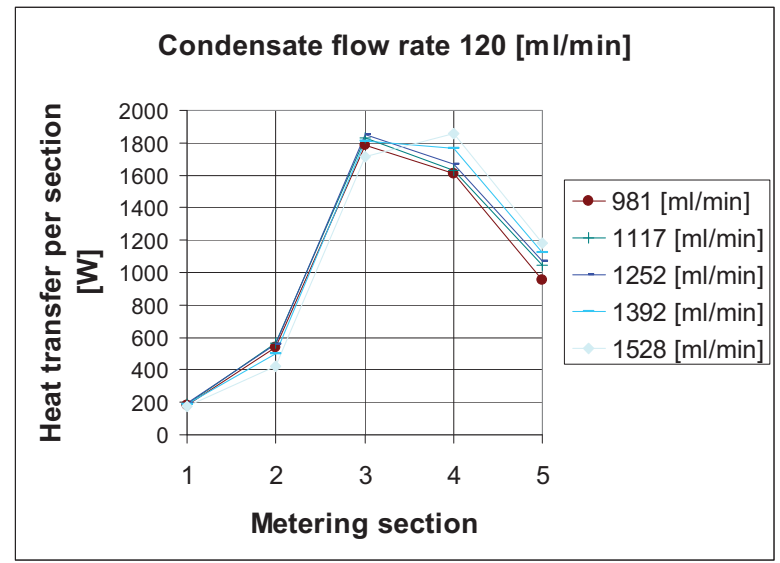

Fig.4 - Heat transfer rates per section at 4.4 bar at different cooling water flow rates and condensate flow rates of $120 \mathrm{ml} / \mathrm{min}$

In the Figure 5 the condensation process at pressure of 6.5 bar is depicted. At the low steam (condensate) flow rate of $28 \mathrm{ml} / \mathrm{min}$, almost no effect of varying cooling water flow rate is observed. However, in case of the high steam flow rate (Figure 5, right chart), the main part of the condensation process occurs in the last two sections ( 4 and $5)$. If that is compared with the results in Figure 3, it is clear that the pressure increase from 4.4 to 6.5 bar causes peak of the heat flow rate move from the middle section to section 5 . So it could be said that the steam pressure has important influence on the condensation process in some cases.

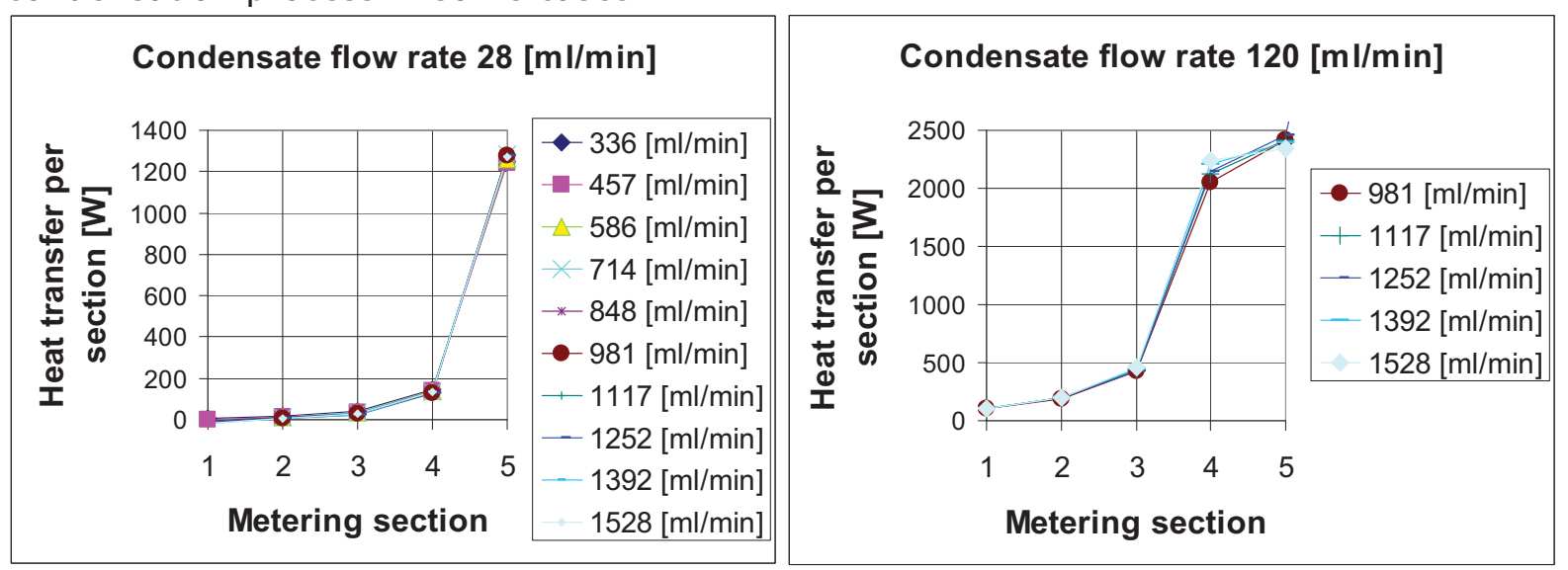

Fig.5 - Heat transfer rates per section at 6.5 bar at different cooling water flow rates and condensate flow rates of $28 \mathrm{ml} / \mathrm{min}$ and $120 \mathrm{ml} / \mathrm{min}$ 
In Figure 6, experiments at steam pressure 8.3 bar are shown. The measurement with $28 \mathrm{ml} / \mathrm{min}$ was not done, because it would not show any difference with respect to lower pressure. Due the possibilities of the steam generating system, the highest measured condensate value was $104 \mathrm{ml} / \mathrm{min}$. Interesting here is the fact how uniformed the chart is. So the condensation process is not so much dependent at the cooling water flow rates in the annular duct.

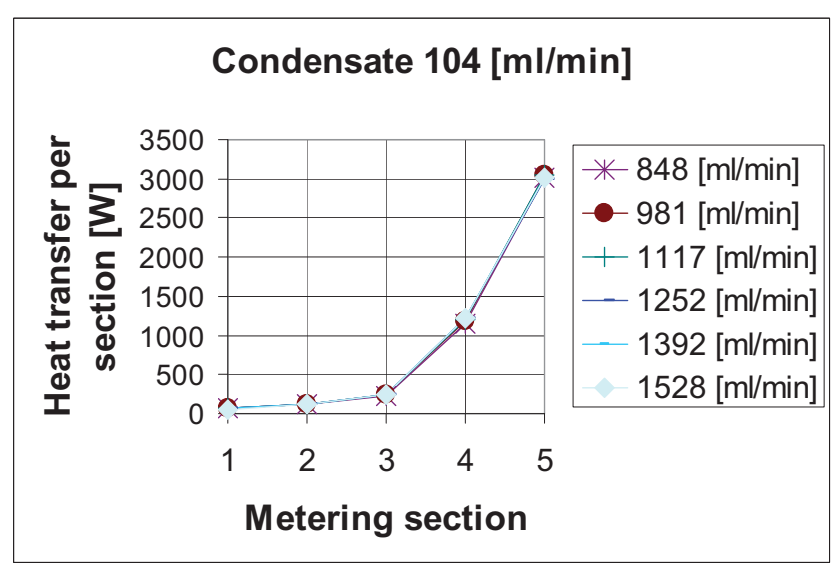

Fig.6 - heat transfer rates per section at 8.3 bar at different cooling water flow rates and condensate flow rates of $104 \mathrm{ml} / \mathrm{min}$
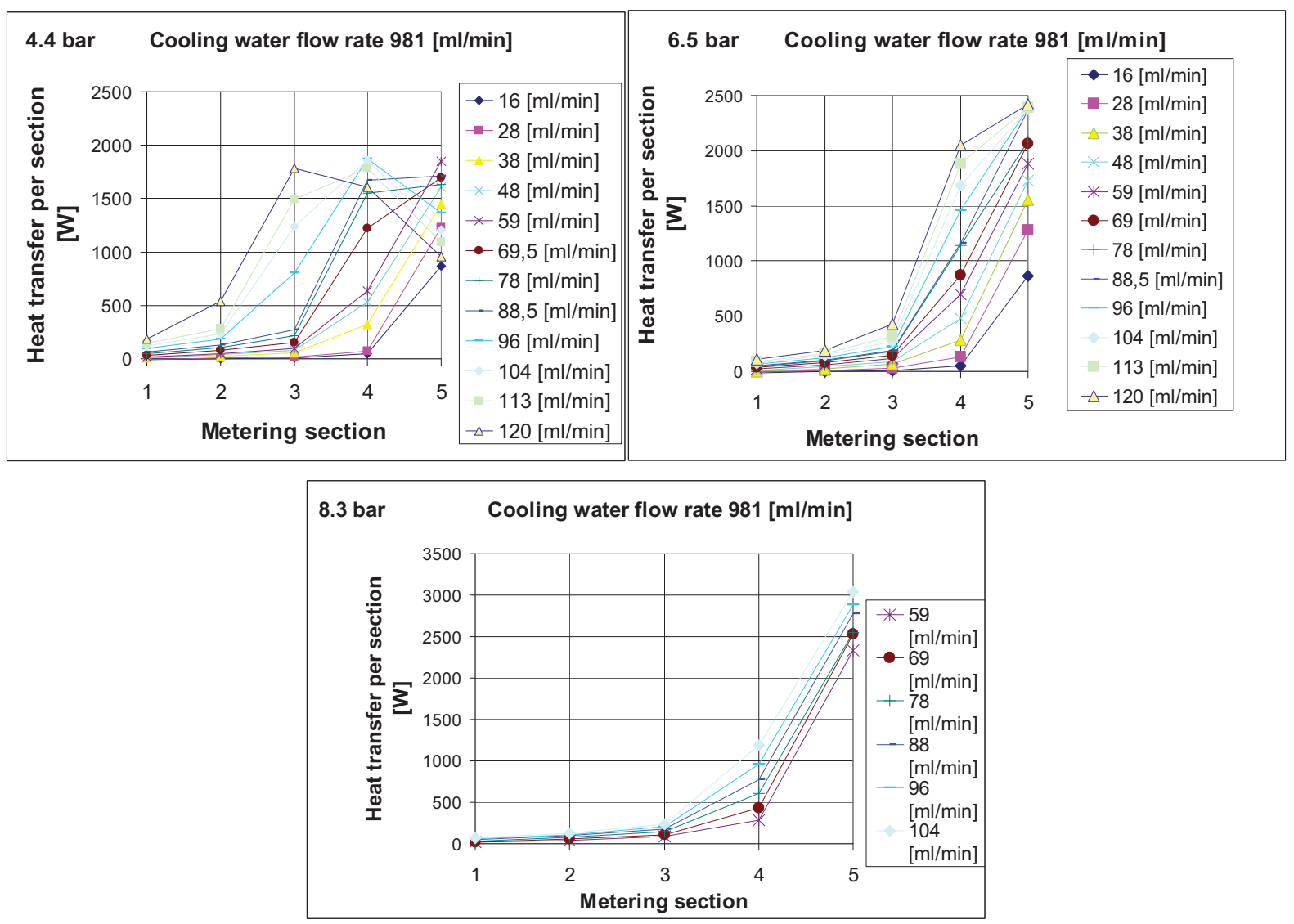

Fig.7 - Heat transfer rates per section at 4.4, 6.5, 8.3 bar at flow rate of $981 \mathrm{ml} / \mathrm{min}$ of the cooling water and different condensate flow rates 
Another point of view was chosen in Figure 7 and Figure 8. Contrary to the previous charts, here the cooling water flow rate is held constant for all charts in each figure. For each chart, the steam pressure is constant. The steam flow rate varies for various curves. It is amazing how due the pressure rise the heat transfer distribution becomes less and less dependent on the condensate flow rate so that the .result get more uniformed. With pressure increase the whole condensation process gets more efficient.
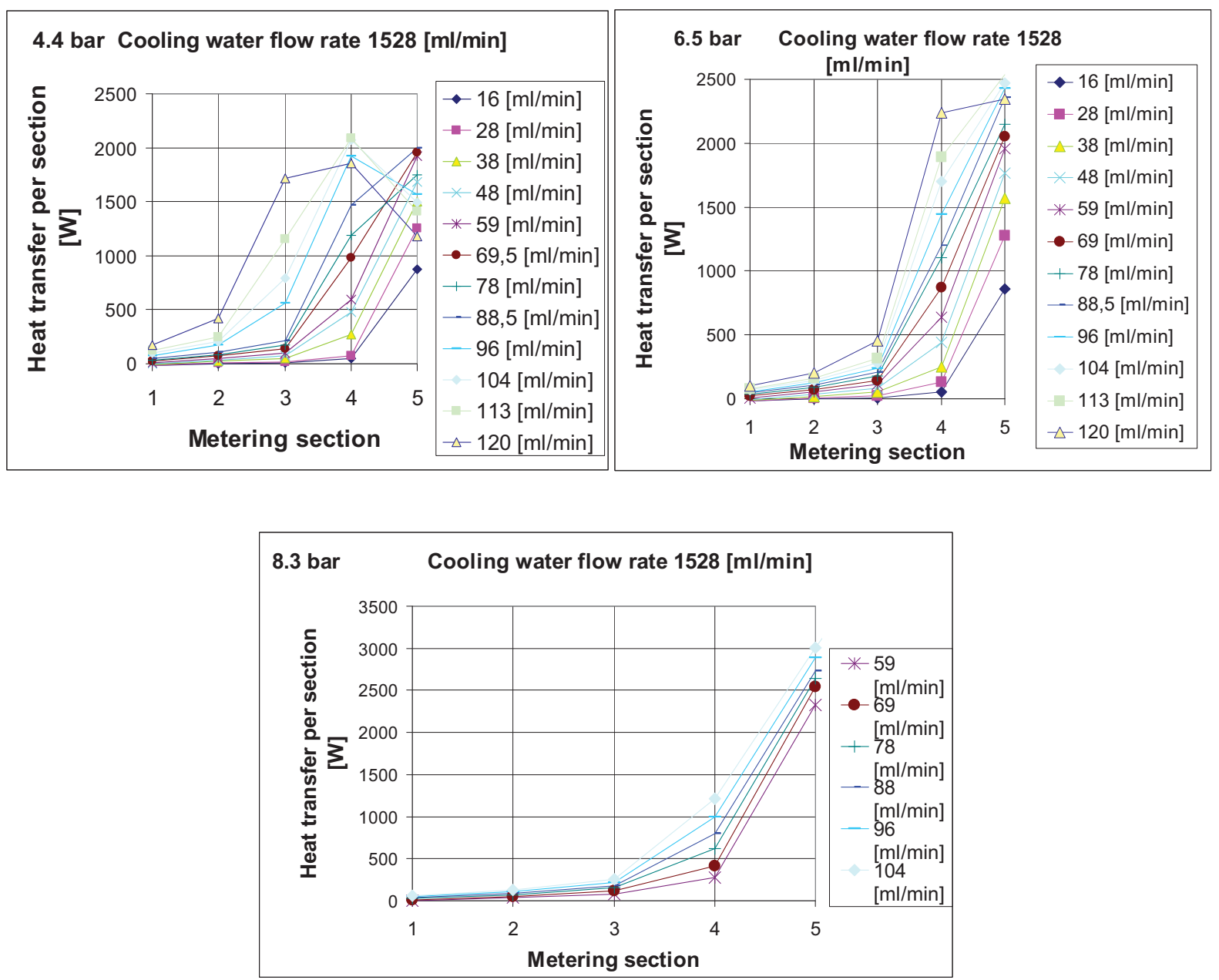

Fig.8 - heat transfer rates per section at 4.4, 6.5, 8.3 bar at flow rate of $1528 \mathrm{ml} / \mathrm{min}$ of the cooling water and different condensate flow rates

Another point of interest was the study of the influence of steam temperature. Here we chose steam flow rate of $59 \mathrm{ml} / \mathrm{min}$ which could be provided by the steam supply system up to high temperatures. In Figure 9 are depicted the result heat transfer rates per section for temperatures from 143 to $245^{\circ} \mathrm{C}$. 


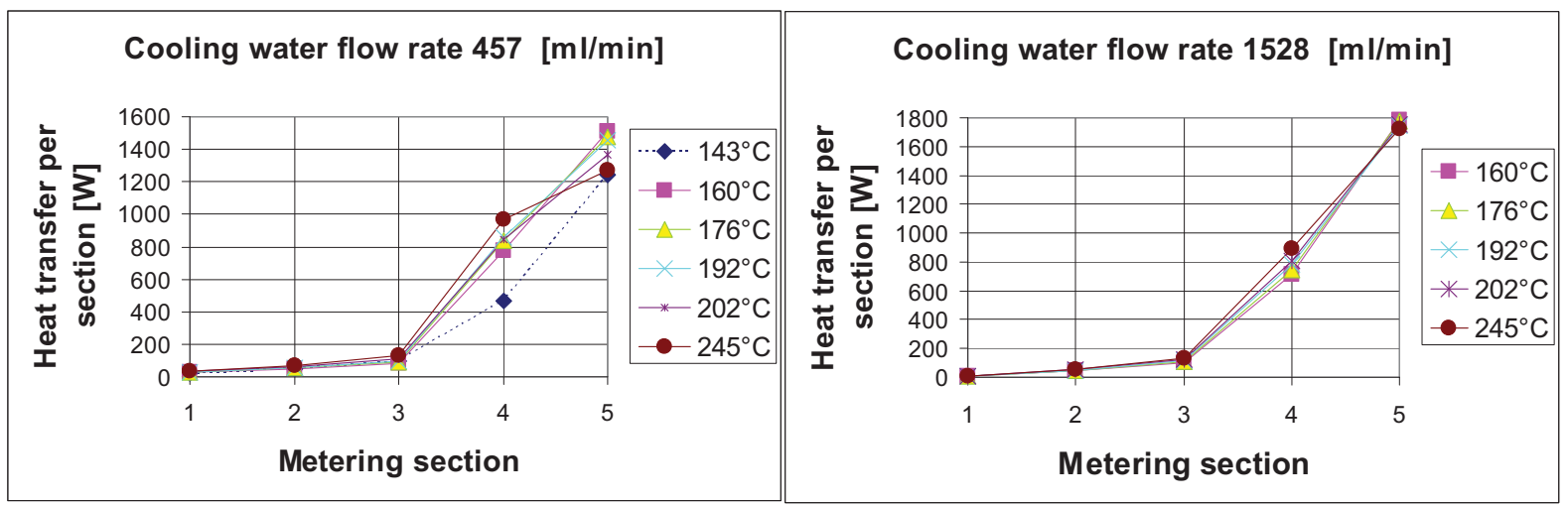

Fig.9 - heat transfer rates per section at 4.4 bar at flow rate of 457 and $1528 \mathrm{ml} / \mathrm{min}$ of the cooling water, a condensate flow rate of $59 \mathrm{ml} / \mathrm{min}$ and different vapour temperatures

The curve at of $143^{\circ} \mathrm{C}$ is shown to illustrate the effect of wet steam at the inlet, which was avoided in all other experiments. Comparison of enthalpy differences on the cooling water and steam sides showed a discrepancy of $30 \%$. Therefore, this data was not considered as valid.

Apart form the invalid $143^{\circ} \mathrm{C}$ curve, the other curves fall on top of each other for both cooling water flow rates. It can be concluded that the inlet temperature has a marginal effect on the heat transfer distribution.

\section{SUMMARY AND FURTHER GOALS}

It was shown that the steam pressure has a significant influence on the condensation heat transfer in a corrugated minichanel tube. The influence of pressure becomes more prominent in cases when it approached the limit necessary for the given flow rate. Most probably the steam pressure drops due to frictional loses. Bubbles occupying nearly the whole cross section appear, reducing the heat transfer rate.

The cooling water velocities (flow rates) have a more significant influence at lower steam pressure. As the pressure rises, this factor became less prominent. The cooling water flow rates are more important in practice, when requirements are given on the outlet temperature of the cooling water. As an example, warm water supply could be 
mentioned which is required to have at least $65^{\circ} \mathrm{C}$ for preventing bacteria growth. So not only the heat transfer is important.

The experimental heat exchanger is able to provide outlet water at $1528 \mathrm{ml} / \mathrm{min}$ temperatures up to $70^{\circ} \mathrm{C}$ at a inside pressure of 6,5 bar and incoming steam temperature of $185^{\circ} \mathrm{C}$ at a flow rate of $120 \mathrm{ml} / \mathrm{min}$. However, the condensate temperature with $40^{\circ} \mathrm{C}$ is somewhat high, because it would mean an energy loss. At these parameters, a heat transfer rate of $5.3 \mathrm{~kW}$ is obtained which respond to a average heat flux of $265 \mathrm{~kW} / \mathrm{m}^{2}$ over the whole minichannel length. The average heat flux over one metering section (30 $\mathrm{cm}$ long) achieved $446 \mathrm{~kW} / \mathrm{m}^{2}$. A further result is that the steam overheating brings minimal influence in the condensation process especially.

Based on the present results, the experimental heat exchanger was modified in order to better capture the distribution of the heat transfer rate along the minichanel tube length. Instead of uniform length of the sections, we prepared shorter sections at the steam inlet, where the heat transfer rate changes most rapidly. Also, the diameter of the outer tube (outer diameter of the annular duct for the cooling water) was reduced to investigate the effect of higher Reynolds number on the heat transfer fate.

The good heat transfer parameters of the present condensation heat exchanger show that application of corrugated minichanel tubes brings a potential of developing very compact, short industrial heat exchangers.

\section{ACKNOWLEDGEMENTS}

We gratefully acknowledge the support by Grant No. 101/09/1633 of the Grant Agency of the Czech Republic and the Research Plan No. AV0Z20760514. The capillary tubes were kindly provided by the company Glazer, Cheb, Czech Republic. We gratefully acknowledge technical assistance by Bohuslav Šmíd (mechanical design) and Miroslav Pavelka (electrical design).

\section{REFERENCES}

[1] KANDLIKAR S., GARIMELLA S.: Heat transfer and fluid flow in minichannels and microchannels, Kidlington, Oxford, UK, Elsevier Ltd, 2006,

[2] SAZIMA M., KMONÍČEK V.: Teplo, Prague, Czech republic, SNTL - Nakladatelství technické literatury, 1989

[3] Revised Release on the IAPWS Industrial Formulation 1997 for the Thermodynamic Properties of Water and Steam, Lucerne, Switzerland, Lucerne. www.iapws.org

[4] Wagner, W., Cooper, J. R., Dittmann, A., Kijima, J., Kretzschmar, H.-J., Kruse, A., Mareš, R., Oguchi, K., Sato, H., Stöcker, I., Šifner, O., Takaishi, Y., Tanishita, I., Trübenbach, J., and Willkommen, Th.: The IAPWS Industrial Formulation 1997 for the Thermodynamic Properties of Water and Steam, page 150-182, Journal of Engineering of Gas Turbines \& Power, Vol. 122, ASME, 2000 